\title{
Design and Simulation DFIM Driven Electrical Vehicles Based on IP Controller
}

\author{
Al-Mayhedee Zubair ${ }^{1}$, Mohammad Abdul Mannan ${ }^{1}$, and Junji Tamura ${ }^{2}$
}

\begin{abstract}
The environment friendly blessings of Electrical Vehicles (EV), human beings are becoming extra involved in the use of them alternatively than the usage of mechanical differentials. In electrical vehicles distinct sorts of electrical machines are used among them DFIM is used in this work. The challenging work is to design of a controller as the output of the motor has to match with vehicle input. So, far, most of the mentioned works have utilized Proportional-Integral (PI) controllers as the speed control. But, the negative aspects of PI controller are properly known, as its design depends on the specific motor parameters and the overall performance is sensitive to system disturbances. The fundamental goal of this paper is to replace the conventional PI controller by means of an IP controller which is successful of dealing with exceedingly nonlinear DFIM motor for high performance application in Electrical Vehicle. The effectiveness of designed IP controller of an electrical differential for an EV system is evaluated through Matlab/Simulink software. In simulation work different road conditions for $\mathrm{EV}$ are considered. After the simulation the designed controller is found to be strong for the speed control application of Electrical Vehicle.
\end{abstract}

Key words: - Electrical Vehicle; Doubly Fed Induction Motor; FOC; IP Controller; PI Controller.

\section{INTRODUCTION}

Since the early years of industrialization, the researchers were faced with "how to control the electric machines at variable speed." Electric drives require high performance, increased reliability, and reduced cost. Among these machines is doubly fed induction machine (DFIM) [1-3] is an asynchronous machine with wound rotor which can be supplied at the same time by the stator and the rotor with external source voltages [4]. It was first studied to be used as a high-speed motor. The many benefits of this machine are: reduced manufacturing cost, relatively simple construction, higher speed and do not require ongoing maintenance. In recent decades, the advances in technology of power electronics and microcomputer, different applications of DFIM became possible. Their interest lies mainly in the speed control options with and without mechanical sensors as well as the regimes in either motor or generator operations

\footnotetext{
Al-Mayhedee Zubair

American International University-Bangladesh

Email: amzubair25@gmail.com

Mohammad Abdul Mannan (Professor)

American International University-Bangladesh

Email: mdmannan@aiub.edu,
}

Junji Tamura (Professor)

Kitami Institute of Technology (KIT), Japan

with flux control powers for hypo and hyper-synchronous features [5]. The DFIM is essentially nonlinear, due to the coupling between the flux and the electromagnetic torque. The vector control or field orientation control allows a decoupling between the torque and the flux [6] [7]. With the field orientation control (FOC) method, induction machine drives are becoming a major candidate in high-performance motion control applications, where servo quality operation is required.

The task comes to researchers on how to manipulate DFIM successfully due to its robustness and non-linearity characteristic. Initially fixed gain PI controllers had been employed by researchers as speed controller of DFIM drive system due to the fact of their simplicity [5, 6, and 7]. However, it is very challenging to decide suitable PI controller parameters in controlling complex non-linear, incompletely modeled or uncertain systems since the speed and the torque of the motor usually change depends on terrain and traffic condition traveled by electric vehicle. Besides, this PI controller will showcase poor transient response thus it's no longer appropriate for this application due to complexity of this system [8]. IP controllers provide many benefits as their design do not need the actual mathematical model of the system and theoretically they are capable of managing any non-linearity of arbitrary complexity [9]. Besides they showcase superb dynamic response. Among the various controllers, IP controller is the simplest and better in terms of response time, insensitivity to parameter and load variations [9], [10]. Sinusoidal Pulse Width Modulation is used with IP Controller to keep the output voltage at the rated voltage and to have better performance.

The paper is organized as follows: In section II mathematical model of the DFIM is presented. In section III, we begin with the DFIM oriented model in view of the vector control; IP controller is presented in section IV and gives the design procedure of the proposed controller with the simulation results given in section V. Finally, some conclusions are drawn in section VI.

\section{DYNAMIC MODELING OF DOUBLY FED INDUCTION MOTOR}

Fig. 1 shows the typical configuration of overall control system of DFIM. Two inverters are used to transmit current from dc source to the stator winding and the rotor windings. The switching action of inverters is performed based on the injecting the controllable voltage in to the stator and the rotor to obtain the desired voltage with desired frequency of both stator and rotor for variable speed operation. 


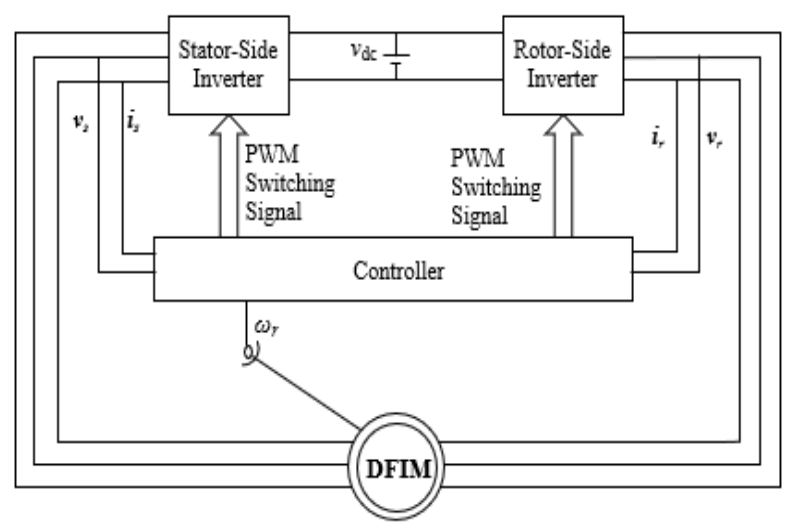

Fig. 1. Overall Block diagram of DFIM Drive System.

Though the two inverters share the same dc bus, they can be operated separately, meaning that both stator and rotor windings can be controlled independently.

Fig. 2 Shows the equivalent circuit diagram of a DFIM in complex vector form in a synchronously rotating $d q$-axes reference frame.

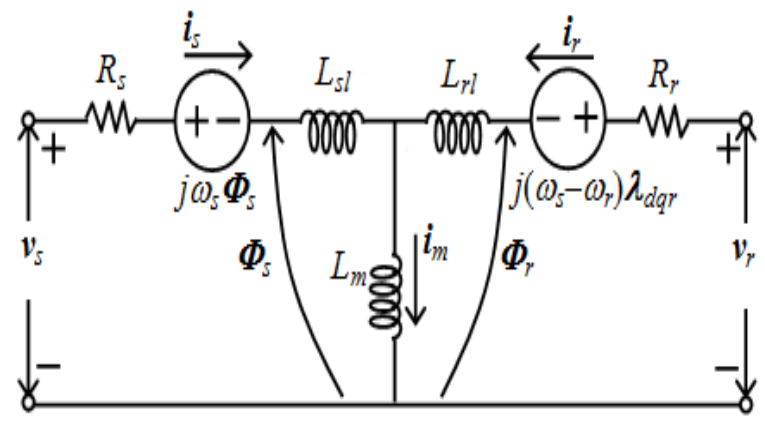

Fig. 2. Complex synchronously rotating $d q$-axes reference frame equivalent circuit of DFIM.

In this figure subscripts " $s$ " and " $r$ " refer to the stator $\&$ rotor windings variable, respectively. $\boldsymbol{v}_{s}=v_{s d}+j v_{s q}$ and $\boldsymbol{v}_{r}=v_{r d}+j v_{r q}$ are the stator and rotor voltage vectors; $\boldsymbol{i}_{s}=i_{s d}+j i_{s q}$ and $\boldsymbol{i}_{r}=$ $i_{r d}+j i_{r q}$ denotes stator and rotor current vectors; $R_{s}$ and $R_{r}$ are the stator and rotor resistance; $L_{m}, L_{s l}, L_{r l}$ are the magnetizing, stator leakage and rotor leakage inductances, respectively; $\boldsymbol{\Phi}_{s}$ $=\Phi_{s d}+j \Phi_{s q}$ and $\Phi_{r}=\Phi_{r d}+j \Phi_{r q}$ are the stator and rotor flux vectors; $\omega_{s}$ is the stator winding electrical angular velocity and $\omega_{r}$ is the rotor winding electrical angular velocity.

Using the fundamental laws of ohm's law and faraday's law, the expressions of stator and rotor voltages with the currents and fluxes in synchronously rotating frame can be given as follows [11-15]:

$$
\begin{aligned}
& v_{s d}=R_{s} i_{s d}+p \Phi_{s d}-\omega_{s} \Phi_{s q} \\
& v_{s q}=R_{s} i_{s q}+p \Phi_{s q}+\omega_{s} \Phi_{s d} \\
& v_{r d}=R_{r} i_{r d}+p \Phi_{r d}-\omega_{r} \Phi_{r q} \\
& v_{r q}=R_{r} i_{r q}+p \Phi_{r q}+\omega_{r} \Phi_{r d} \\
& \Phi_{s d}=L_{s} i_{s d}+L_{m} i_{r d} \\
& \Phi_{s q}=L_{s} i_{s q}+L_{m} i_{r q} \\
& \Phi_{r d}=L_{r} i_{r d}+L_{m} i_{s d} \\
& \Phi_{r q}=L_{r} i_{r q}+L_{m} i_{s q}
\end{aligned}
$$

In the above equations subscripts $d$ and $q$ are represented for $d$-axis quantities and $q$-axis quantities, respectively, and $p$ is represented $d / d t$.

The electromagnetic torque and the mechanical dynamics can be given by:

$T_{e}=K_{t}\left[i_{s q} \Phi_{r d}-i_{s d} \Phi_{r q}\right]$

$T_{e}=\frac{J_{m}}{P_{n}} p \omega_{m}+\frac{B_{m}}{P_{n}} \omega_{m}+T_{m}$

where, $K_{t}=\frac{P_{n} L_{m}}{L_{m}}, J_{m}$ is inertia, $B_{m}$ is friction coefficient and $P_{n}$ is the number of pole pair.

Using the above Eqs. (2.1) to (2.10), the state-space equations of a DFIM can be written as follows:

$p i_{s d}=-K_{2} i_{s d}+K_{4} \Phi_{r d}+\omega_{s} i_{s q}+K_{3} \omega_{m} \Phi_{r q}+K_{1} v_{s d}-K_{3} v_{r d}$ (2.11)

$p i_{s q}=-K_{2} i_{s q}+K_{4} \Phi_{r q}-\omega_{s} i_{s d}-K_{3} \omega_{m} \Phi_{r d}+K_{1} v_{s q}-K_{3} v_{r q}$

$p \Phi_{r d}=K_{6} i_{s d}-K_{5} \Phi_{r d}+\omega_{r} \Phi_{r q}+v_{r d}$

$p \Phi_{r q}=K_{6} i_{s q}-K_{5} \Phi_{r q}-\omega_{r} \Phi_{r d}+v_{r q}$

$p \omega_{m}=-K_{7} \omega_{m}+K_{9} i_{s q} \Phi_{r d}-K_{9} i_{s d} \Phi_{r q}-K_{8} T_{L}$

where, $K_{1}=\frac{1}{\sigma L_{s}}, K_{2}=\frac{R_{s} L_{r}^{2}+R_{r} L_{m}^{2}}{\sigma L_{s} L_{r}^{2}}$,

$K_{3}=\frac{K_{1} L_{m}}{L_{r}}, K_{4}=\frac{K_{3} R_{r}}{L_{r}}, K_{5}=\frac{R_{r}}{L_{r}}$,

$K_{6}=K_{5} L_{m}$

$K_{7}=\frac{B_{m}}{J_{m}} \cdot K_{8}=\frac{P_{n}}{J_{m}}, K_{9}=K_{8} K_{t}$

The Matlab/Simulink model of DFIM has been developed using Eqs. (2.11) to (2.15).

\section{VECTOR CONTROL OF DFIM}

A vector controlled doubly fed induction machine is a captivating solution for excessive limited speed range electric powered force and era application, it consists in guiding an electromagnetic flux of the DFIM along the axis $d$ or $q[12$, 13]. In this paper, we select the direction of reference $(d, q)$ in accordance to the direct stator flux vector $\Phi_{s d}$, so the model of steady-state DFIM will be simplified as follows:

$$
\begin{aligned}
& V_{s d}=R_{s} I_{s d}-\omega_{s} \Phi_{s q} \\
& V_{s q}=R_{s} I_{s q}+\omega_{s} \Phi_{s d} \\
& V_{r d}=R_{r} I_{r d}-\omega_{r} \Phi_{r q} \\
& V_{r q}=R_{r} I_{r q}+\omega_{r} \Phi_{r d} \\
& \text { where, } \omega_{r}=\omega_{s}-\omega
\end{aligned}
$$

The magnetization of machine is certain by way of the rotor direct current, so the stator current in the $d$-axis is taken to zero $\left(i_{s d}=0\right)$. The current and voltage in the stator are then in phase: $V_{s q}=V_{s}$ and $I_{s q}=I_{s}$. In this case we acquire a unity power factor at the stator, so the stator reactive electricity is zero i.e. $Q_{s}=0$. Vector control consists in orienting the stator 
flux. Thus, it results the constraints given below in Eq. (3.5). The stator flux is oriented on the $q$ axis.

$$
\left.\begin{array}{l}
\Phi_{s d}=\Phi_{s} \\
\Phi_{s q}=0
\end{array}\right\}
$$

Using the constraints of vector control of Eq. (3.5), the developed torque of Eq. (2.9) can simply be written as follows:

$$
T_{e}=P_{n} \Phi_{s} I_{s q}
$$

According to the previous mathematical derivations, the reference for stator currents and rotor currents can be obtained. Based on the vector control strategy these references are summarized in Table $\mathbf{1 .}$

Table 1: Control strategy to the DFIM model

\begin{tabular}{|c|c|}
\hline Objectives & References \\
\hline$\Phi_{s d}=\Phi_{s}=\Phi_{s n}$ & ${ }_{i r d}^{r e f}=\Phi_{s n} / L_{m}$ \\
\hline$\Phi_{s q}=0$ & $i_{r q}^{r e f}=-\left(L_{s} / L_{m}\right) i_{s q-r e f}$ \\
\hline$Q_{s}=0,(\cos \varphi=1)$ & ${ }^{r e f}=0$ \\
\hline$T_{e}=T_{e}^{r e f}$ & ${ }_{i s q}^{r e f}=T_{e}^{r e f} / K_{T e m}$ \\
\hline
\end{tabular}

\section{ELECTRICAL VEHICLES MECHANICAL DYNAMICS}

\section{Aerodynamics Force and Torque}

The aerodynamics force which is due to the friction of the vehicle body, moving through the air is given by:

$$
F_{\text {aero }}=\frac{1}{2} \rho_{\text {air }} A_{f} C_{d} v_{h}^{2}
$$

The aerodynamics torque is:

$$
T_{\text {aero }}=F_{\text {aero }} R_{w}=\frac{1}{2} \rho_{\text {air }} A_{f} C_{d} v_{h}^{2} R_{w}
$$

\section{Rolling force}

The rolling resistance is primarily due to the traction of the tire on the road. Friction in bearing and the gearing systems also play their part. The rolling resistance is appositely constant, depend on vehicle speed. It is proportional to vehicle weight the equation is.

$$
F_{\text {roll }}=F_{\text {tire }}=M g f_{v}
$$

The rolling torque is:

$$
T_{\text {roll }}=T_{\text {tire }}=F_{\text {roll }} R_{w}=F_{\text {tire }} R_{w}=M g f_{v} R_{w}
$$

\section{Hill Climbing or Slope Force}

The force needed to drive the vehicle up a slope is the most straightforward to find it is simply the component of the vehicle weight that acts along the slop. The climbing or slope force can be given as:

$$
F_{\text {slope }}=F_{\text {climb }}=M g \sin \beta
$$

The slope torque is:

$$
\begin{aligned}
T_{\text {slope }} & =T_{\text {climb }}=F_{\text {slope }} R_{w} \\
& =F_{\text {climb }} R_{w}=M g R_{w} \sin \beta
\end{aligned}
$$

\section{Total Force}

Total vehicle or resistance force is:

$$
F_{v}=F_{\text {res }}=F_{\text {aero }}+F_{\text {roll }}+F_{\text {slope }}+F_{\text {la }}++F_{\text {wa }}
$$

$F_{l a}$ and $F_{w a}$ will be negative if the vehicle is slowing down and the $F_{\text {slope }}$ is negative if it is going downhill.

\section{MODELING OF ELECTRONIC VEHICLE DIFFERENTIAL}

\section{The Ackerman Principle}

A simplified, trigonometry-based Ackerman steering model was used in this paper. There are three main assumptions in this analysis: $(i)$ the front wheels are considered passive wheels so that the velocity path defined by the rear wheels can be perfectly tracked by the front wheels; (ii) since the rear wheels have no slip action, the velocity of the wheels are represented as a function of their radius; and (iii) the vehicle rotation speed is half of the differential speed between the two traction rear wheels.

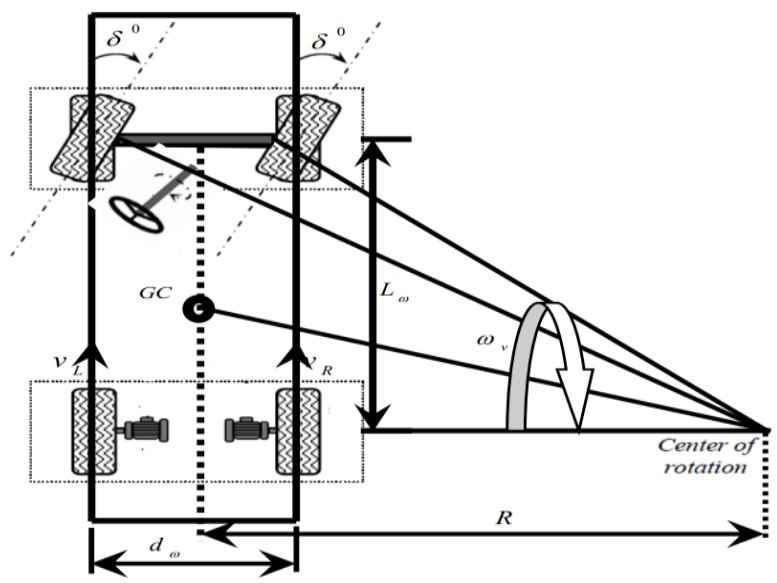

Fig. 3. Vehicle structure in a turn.

Fig. 3 shows the vehicle structure when taking a turn, where $L_{\omega}$ represents the wheelbase, $\delta$ is the steering angle, $d_{\omega}$ is the distance between the wheels of the same axle, and $\omega_{R}$ and $\omega_{L}$ are the angular speeds of the right and left wheel drives, respectively.

As shown in Fig. 3, the linear speed of each wheel drive is expressed as a function of the vehicle speed and the radius of the curve, which are derived through Eqs. (5.1) and (5.2) and given by:

$$
\begin{aligned}
& v_{L}=\omega_{v}\left(R+\frac{d_{\omega}}{2}\right)=\omega_{v L} R \\
& v_{R}=\omega_{v}\left(R-\frac{d_{\omega}}{2}\right)=\omega_{v R} R
\end{aligned}
$$

The radius of the curve depends on the wheelbase and steering angle $(\delta)$ expressed by:

$$
R=\frac{L_{\omega}}{\tan \delta}
$$

Substituting Eq. (5.3) in Eqs. (5.1) and (5.2), we obtain the angular speed in each wheel drive given by: 


$$
\begin{aligned}
& \omega_{v L}=\frac{L_{\omega}+\left(d_{\omega} / 2\right) \tan \delta}{L_{\omega}} \omega_{v} \\
& \omega_{v R}=\frac{L_{\omega}-\left(d_{\omega} / 2\right) \tan \delta}{L_{\omega}} \omega_{v}
\end{aligned}
$$

The difference between the angular speeds of the wheel drives is expressed by Eq. (5.6). The signal of the steering angle indicates the curve direction and is derived using Eq. (5.4).

$$
\left.\begin{array}{lll}
\Delta \omega=\omega_{v L}-\omega_{v R}= & \frac{d_{\omega} \tan \delta}{L_{\omega}} \omega_{v} \\
\delta>0 & \Rightarrow & \text { Turn right } \\
\delta=0 & \Rightarrow & \text { Straight ahead } \\
\delta<0 & \Rightarrow & \text { Turn left }
\end{array}\right\}
$$

When the vehicle arrives at the start of a curve, the driver applies a steering angle on the wheels. The electronic differential, however, acts immediately on the two motors, reducing the speed of the inner wheel and increasing the speed of the outer wheel. The driving wheel angular speeds are given by:

$$
\begin{aligned}
& \omega_{r L}^{*}=\omega_{v}^{*}+\frac{\Delta \omega}{2} \\
& \omega_{r R}^{*}=\omega_{v}^{*}-\frac{\Delta \omega}{2}
\end{aligned}
$$

Meanwhile, the speed references of the two motors are given by:

$$
\begin{aligned}
& \omega_{r L}^{*}=N_{g} \omega_{v L}^{*} \\
& \omega_{r R}^{*}=N_{g} \omega_{v R}^{*}
\end{aligned}
$$

\section{DESIGN OF CONTROLLER SYSTEM}

In order to design the current controllers, we have the following expressions by rearranging the Eqs. (2.11) to (2.13):

$$
\begin{aligned}
& \sigma L_{s} p i_{s d}+R_{s} i_{s d}=u_{s d}-C_{s d}=v_{c s d} \\
& \sigma L_{s} p i_{s q}+R_{s} i_{s q}=u_{s q}-C_{s q}=v_{c s q} \\
& \sigma L_{r} p i_{r d}+R_{r} i_{r d}=u_{r d}-C_{r d}=v_{c r d} \\
& \sigma L_{r} p i_{r q}+R_{r} i_{r q}=u_{r q}-C_{r q}=v_{c r q}
\end{aligned}
$$

The decoupling compensation terms $C_{s d}, C_{s q}, C_{r d}$, and $C_{r q}$, and the intermediate voltages $u_{s d}, u_{s q}, u_{r d}$, and $u_{r q}$, in Eqs. (6.1) to (6.4) are given as follows:

$$
\begin{aligned}
& C_{s d}=-\frac{R_{r} L_{m}}{L_{r}} i_{r d}-\omega_{s} \Phi_{s q}+\frac{L_{m}}{L_{r}} \omega_{r} \Phi_{r q} \\
& C_{s q}=-\frac{R_{r} L_{m}}{L_{r}} i_{r q}+\omega_{s} \Phi_{s d}-\frac{L_{m}}{L_{r}} \omega_{r} \Phi_{r d} \\
& C_{r d}=-\frac{R_{S} L_{m}}{L_{s}} i_{s d}+\frac{L_{m}}{L_{s}} \omega_{s} \Phi_{s q}-\omega_{r} \Phi_{r q} \\
& C_{r q}=-\frac{R_{S} L_{m}}{L_{s}} i_{s q}-\frac{L_{m}}{L_{s}} \omega_{s} \Phi_{s d}+\omega_{r} \Phi_{r d}
\end{aligned}
$$

$$
\begin{aligned}
& u_{s d}=v_{s d}-\frac{L_{m}}{L_{r}} v_{r d} \\
& u_{s q}=v_{s q}-\frac{L_{m}}{L_{r}} v_{r q} \\
& u_{r d}=v_{r d}-\frac{L_{m}}{L_{s}} v_{s d} \\
& u_{r q}=v_{r q}-\frac{L_{m}}{L_{s}} v_{s q}
\end{aligned}
$$

With the constraints of vector control of Eq. (3.5), the mechanical dynamics of Eq. (2.10) with Eq. (2.9) can be written as follows:

$p \omega_{m}+\frac{B_{m}}{J_{m}} \omega_{m}=\frac{P_{n}}{J_{m}} T_{e}-\frac{P_{n}}{J_{m}} T_{m}$

It is evident from Eq. (6.14) that the speed of a DFIM can be control by controlling the electromagnetic torque of DFIM. Then the reference for stator $q$-axis current can be generated from the reference of electromagnetic torque which is the output of speed controller.

Using Eqs. (6.1) to (6.4) and $s$-domain of Laplace transformation, the open-loop transfer function for four different current controllers can be given as follows:

$$
\begin{aligned}
& T_{s d}=T_{s q}=\frac{B_{s}}{s+A_{s}} \\
& T_{r d}=T_{r q}=\frac{B_{r}}{s+A_{r}}
\end{aligned}
$$

Considering the load torque $T_{m}$ as a step function the openloop transfer function for speed controller from Eq. (6.14) is obtained as follows:

$$
T_{\omega}=\frac{B_{\omega}}{s+A_{\omega}}
$$

In Eqs. (6.15) to (6.17)

$$
\begin{aligned}
& T_{s d}=\frac{I_{s d}(s)}{V_{c s d}(s)}, T_{s q}=\frac{I_{s q}(s)}{V_{c s q}(s)}, \quad T_{\omega}=\frac{\omega_{m}(s)}{T_{e}(s)}, \\
& A_{s}=\frac{1}{\sigma T_{s}}, \quad B_{s}=\frac{1}{\sigma T_{s} R_{s}}, \quad T_{r d}=\frac{I_{r d}(s)}{V_{c r d}(s)}, \\
& T_{r q}=\frac{I_{r q}(s)}{V_{c r q}(s)}, \quad A_{r}=\frac{1}{\sigma T_{r}}, \quad B_{r}=\frac{1}{\sigma T_{r} R_{r}}, \\
& A_{\omega}=\frac{B_{m}}{J_{m}}, B_{\omega}=\frac{P_{n}}{J_{m}}, T_{s}=\frac{L_{s}}{R_{s}}, T_{r}=\frac{L_{r}}{R_{r}} .
\end{aligned}
$$

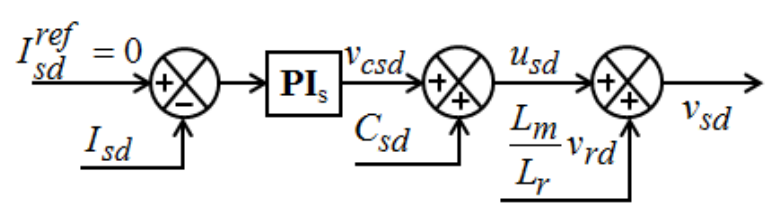

(a) $d$-axis current controller

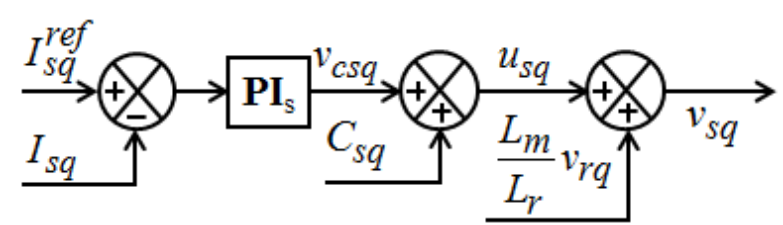

(b) $q$-axis current controller 
Fig. 4. Block diagram of stator current controller.



(a) $d$-axis current controller



(b) $q$-axis current controller

Fig. 5. Block diagram of rotor current controller.

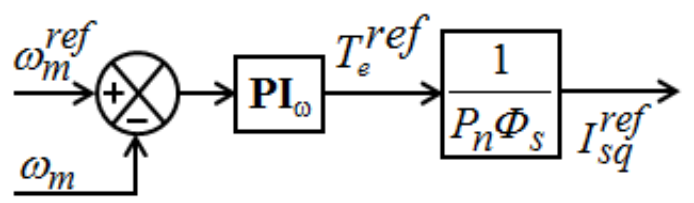

Fig. 6. Block diagram of speed controller of a DFIM.

To obtain the $d$-axis and $q$-axis stator and rotor voltage with the implementation of vector control and based on the Eqs. (6.1) to (6.13), the block diagrams of stator and rotor current controllers are shown in Fig. 4 and Fig. 5. Similarly, the speed controller based on PI and the calculation procedure of reference stator $q$-axis current is shown in Fig. 6.

The generic form of open-loop transfer function Eqs. (6.15) to (6.17) for speed and currents controllers can be written as follows:

$$
G_{o}=\frac{B}{s+A}
$$

The transfer function of PI controller and IP controller are given as follows:

$$
\begin{aligned}
& G_{P I}(s)=\left(K_{P}+\frac{K_{I}}{s}\right) e(s) \\
& G_{I P}(s)=\frac{K_{I}}{s} e(s)-K_{P} a(s)
\end{aligned}
$$

Where, $e(s)=r(s)-a(s), a(s)$ is actual value, $r(s)$ is reference value, $K_{P}$ is proportional gain and $K_{I}$ is the integral gain. Combining the open-loop transfer function and controller transfer function the closed-loop transfer function can be written as follows:

$$
\begin{aligned}
& G_{c P I}(s)=\frac{K_{P} B s+K_{I} B}{s^{2}+\left(A+B K_{P}\right) s+B K_{I}} \\
& G_{c I P}(s)=\frac{B K_{I}}{s^{2}+\left(A+B K_{P}\right) s+B K_{I}}
\end{aligned}
$$

Considering two poles $\alpha_{1}$ and $\alpha_{2}$ (and they are chosen as $\alpha_{1}=$ $\alpha_{2}$ ) in the left-half of complex plane the gain of PI and IP controller can be calculated as follows:

$$
\left.\begin{array}{l}
K_{P}=\frac{2 \alpha_{1}-A}{B} \\
K_{I}=\frac{\alpha_{1}^{2}}{B}
\end{array}\right\}
$$

It has been seen from thee closed-loop transfer function of Eq. (6.21) for PI controller that a zero is placed in the lefthalf plane. The overshoot problem of PI controller is raised due to the zero and the overshoot is increased as the proportional gain increased. On the other hand, the zero of PI controller can be eliminated by changing the structure which becomes as IP controller. The overshoot problem can be minimized by using IP controller instead of PI controller.

\section{SIMULATION \& RESULT}

Tables 2 and $\mathbf{3}$ show the parameters of DFIM which used in the simulation test. The simulation has been carried out using Matlab/ Simulink and IP Toolbox. From the Graphs we can see when car will turn left then the right side speed will be increased and for left side it will be vice versa. When the car will go to up hills it will increase its torque and for down wards the torque will be decreased.

Table 2: Rating and Parameters of the Vehicle

\begin{tabular}{|l|l|l|}
\hline$R_{w}$ & Wheel radius & $0.32 \mathrm{~m}$ \\
\hline$H$ & Total transmission efficiency & $98 \%$ \\
\hline$M$ & Vehicle mass & $1300 \mathrm{Kg}$ \\
\hline $\mathrm{C}_{\mathrm{d}}$ & Aerodynamic coefficient & 0.32 \\
\hline $\mathrm{A}$ & Vehicle frontal are & $2.6 \mathrm{~m}^{2}$ \\
\hline $\mathrm{f}_{\mathrm{r}}$ & Vehicle friction coefficient & 0.01 \\
\hline $\mathrm{L}_{\mathrm{w}}$ & $\begin{array}{l}\text { Distance between two wheels } \\
\text { and axes }\end{array}$ & $2.5 \mathrm{~m}$ \\
\hline $\mathrm{D}_{\mathrm{w}}$ & $\begin{array}{l}\text { Distance between the back } \\
\text { and the front wheel }\end{array}$ & 1.5 \\
\hline
\end{tabular}

Table 3: Ratings and Parameters of the DFIM

\begin{tabular}{|l|l|}
\hline Stator resistance, $R_{s}$ & $35.52 \mathrm{~m} \Omega$, \\
\hline Rotor resistance, $R_{\mathrm{r}}$ & $20.92 \mathrm{~m} \Omega$, \\
\hline Rated speed, Nm & $1500 \mathrm{rpm}$ \\
\hline Motor moment of inertia, J & $0.001 \mathrm{Kg}-\mathrm{m}^{2}$ \\
\hline$B_{m}$ & $0.07 \mathrm{~N} /(\mathrm{rad} / \mathrm{s})$ \\
\hline Stator inductance, $L_{\mathrm{s}}$ & $15.45 \mathrm{mH}$ \\
\hline Roto inductance, $L_{\mathrm{r}}$ & $15.45 \mathrm{mH}$ \\
\hline Mechanical inductance $L_{m}$ & $15.1 \mathrm{mH}$ \\
\hline$V_{d c}$ & $400 \mathrm{~V}$ \\
\hline
\end{tabular}

\section{Case of Left and Right Slope (up-hill and down-hill)} Situations:

In this simulation the following situations are considered:

(i) The vehicle start at $\mathrm{t}=0$ and its speed up by pressing the accelerator.

(ii) at $t=2 \mathrm{~s}$ it is consider that the vehicle should moves to uphill side within angle of $\beta=10^{\circ}$.

(iii) at $t=4 \mathrm{~s}$ it is consider that the vehicle should follow the normal condition so $\beta=0^{\circ}$.

(iv) at $t=6 \mathrm{~s}$ it is consider that the vehicle should moves to down side within angle of $\beta=-10^{\circ}$.

(v) at $t=8 \mathrm{~s}$ it is consider that the vehicle should follow the normal condition so $\beta=0^{\circ}$. 
(vi) at $t=10 \mathrm{~s}$ it is consider that the vehicle should stop by released the accelerator.

Fig. 7 (a and b) and Fig. 8 (a and b) represents the transient simulation results of speed and torque (load and electromagnetic torque) for the up-hill and down-hill road situation. In this simulation the following situations are considered: the vehicle runs in the up-hill condition when the slope torque is positive and over all torque is increased and the vehicle runs in the down-hill condition when the slope torque is negative and over all torque is decreased. Fig. 7 and Fig. 8 show the performance of speed for PI controller and IP controller. The performance of both controllers is almost similar at steady-state conditions. But it is clear from these figures that the overshoot problem is totally vanished in the performance of IP controller.

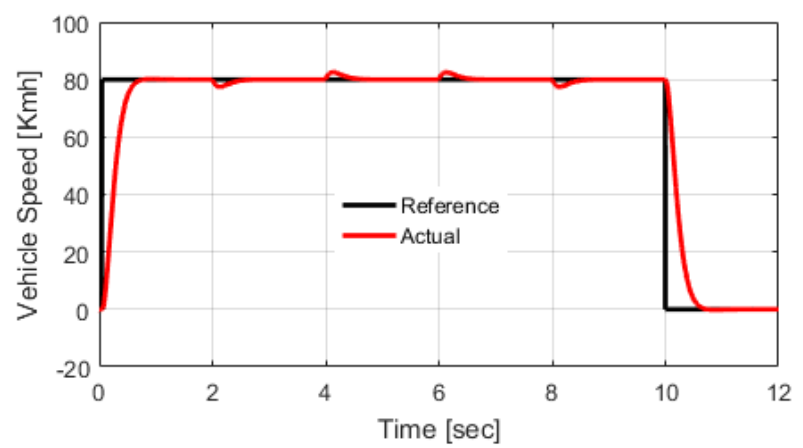

(a) Speed response with IP controller

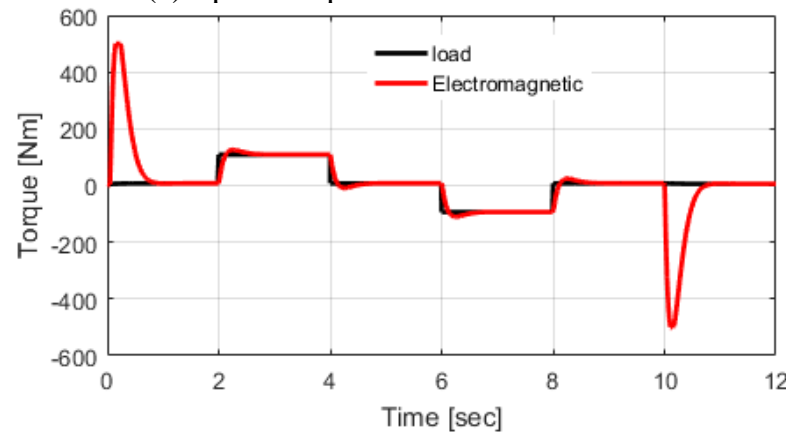

(b) Torque response with IP controller

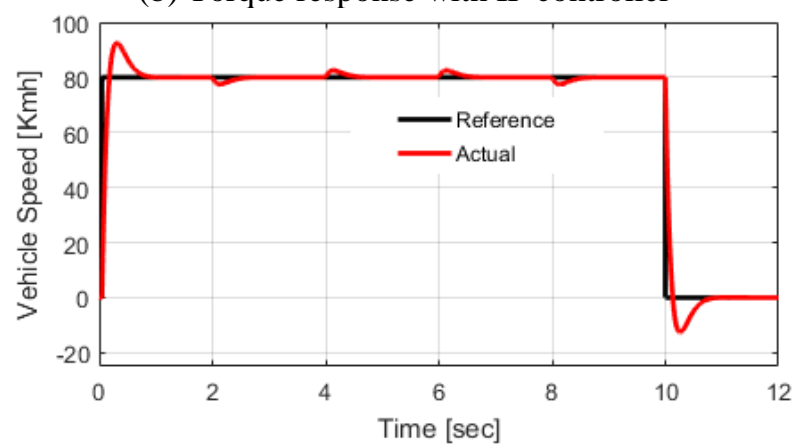

(c) Speed response with PI controller



(d) Torque response with PI controller
Fig. 7: Transient response of left side motor for slop road.

When the vehicle goes to up-hill direction, the load torque increased as shown in Fig. 7(a). Due to the increase of load torque the speed is falling as shown in Fig. 7(a). The response of motors for down-hill condition is just reverse of up-hill condition as shown in Fig. 7(a) and Fig. 8(a). In this case, the load torque which is considered as disturbance for motor is changed drastically. Thus, it can be stated that the proposed IP controller performance is robust under the variation of disturbances.

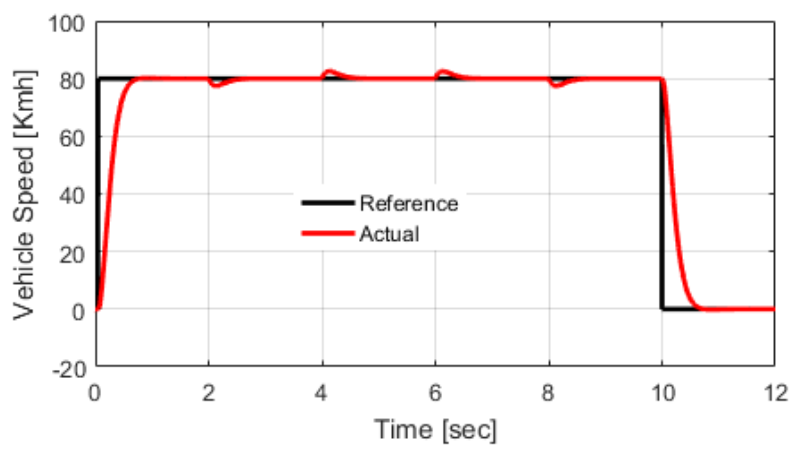

(a) Speed response with IP controller

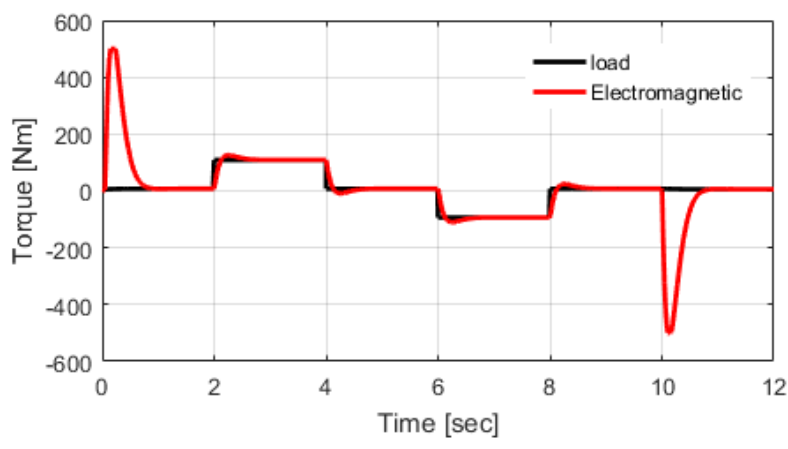

(b) Torque response with IP controller

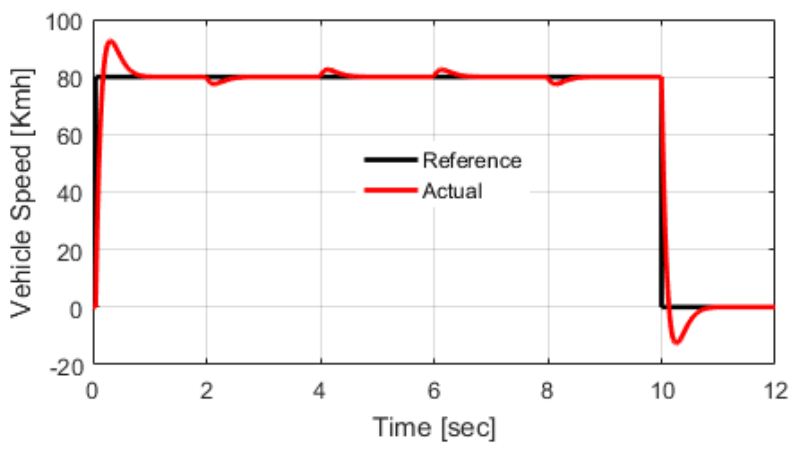

(c) Speed response with PI controller

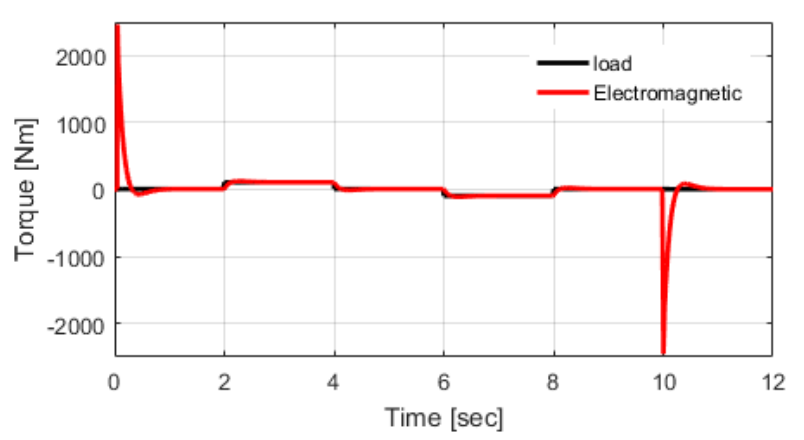

(d) Torque response with PI controller

Fig. 8: Transient response of right side motor for slop road. 


\section{Case of Left and Right Curved Situations:}

In this simulation the following situations are considered:

(i) The vehicle start at $t=0$ and its speed up by pressing the accelerator.

(ii) at $t=2 \mathrm{~s}$ it is consider that the vehicle should moves to right side within angle of $\delta=10^{\circ}$.

(iii) at $t=4 \mathrm{~s}$ it is consider that the vehicle should follow the normal condition so $\delta=0^{\circ}$.

(iv) at $t=6 \mathrm{~s}$ it is consider that the vehicle should moves to left side within angle of $\delta=-10^{\circ}$.

(v) at $t=8 \mathrm{~s}$ it is consider that the vehicle should follow the normal condition so $\delta=0^{\circ}$.

(vi) at $t=10 \mathrm{~s}$ it is consider that the vehicle should stop by released the accelerator.

Fig. 9 (a and b) and Fig. 10 (a and b) represents the transient simulation results of speed and torque (load and electromagnetic torque) for the left curved and right curved road situation. In this simulation work, the following situations are considered: the road will right curve where $\delta>$ 0 and left curved where $\delta<0$. When the road is right curved the speed of left side wheel should be increased and the speed of right side wheel should be decreased. To turn the right side, it is seen from Fig. 9 (a) and $\mathbf{1 0}$ (a), that the speed of left side wheel is increased and the speed of right side wheel is decreased.

In the transient moment of change of speed the left side motor electromagnetic torque is increased to accelerate as shown in Fig. 9(b) and the right side motor electromagnetic torque is decreased to decelerate as shown in Fig. 10(b). So, it is cleared that the vehicle can properly move right curved road by employing the DFIM based designed Electrical Vehicle with the help of the proposed IP controller system. The reverse scenario is obtained for the left curved road situation as shown in Fig. 9 and Fig. 10. These figures show the performance of electromagnetic torque with applied load torque. Since the overshoot is occurred in PI controller the change of electromagnetic torque is larger as compared with the same performance in case of IP controller.

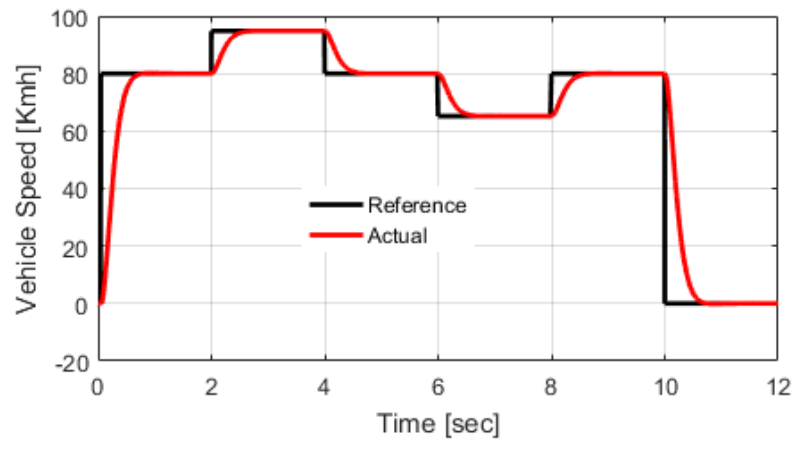

(a) Speed response with IP controller

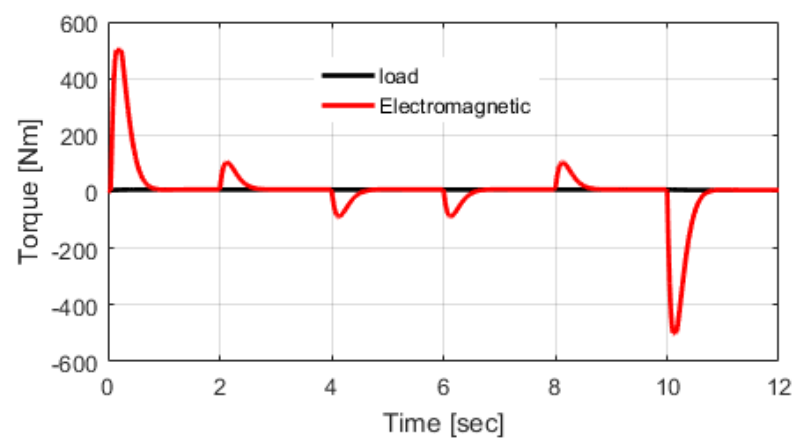

(b) Torque response with IP controller

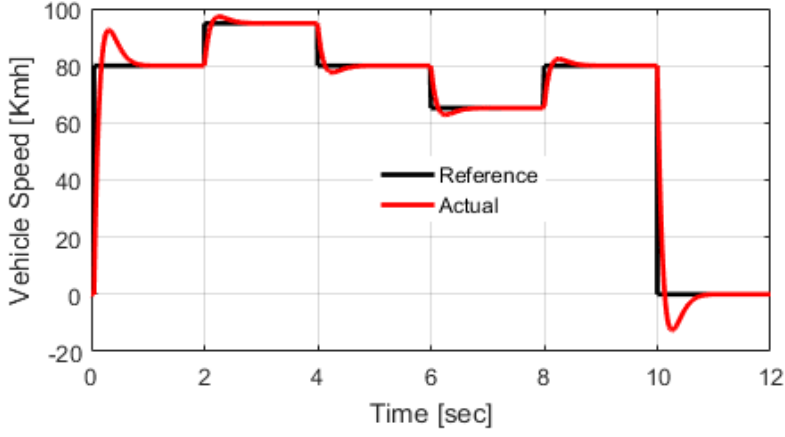

(c) Speed response with PI controller

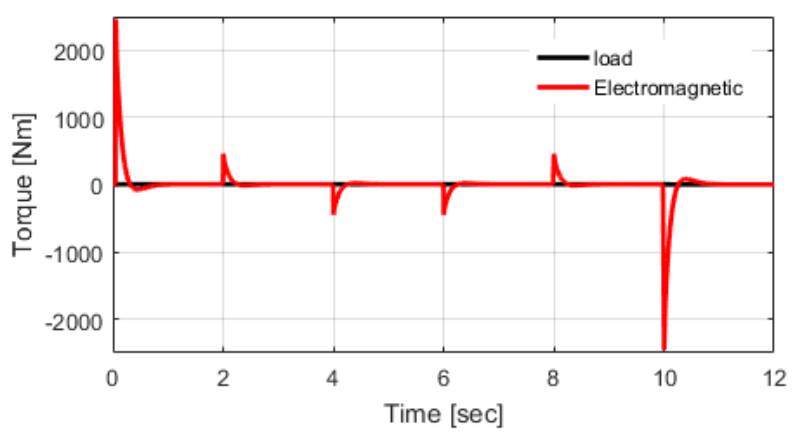

(d) Torque response with PI controller

Fig. 9: Transient response of left side motor for curved road.

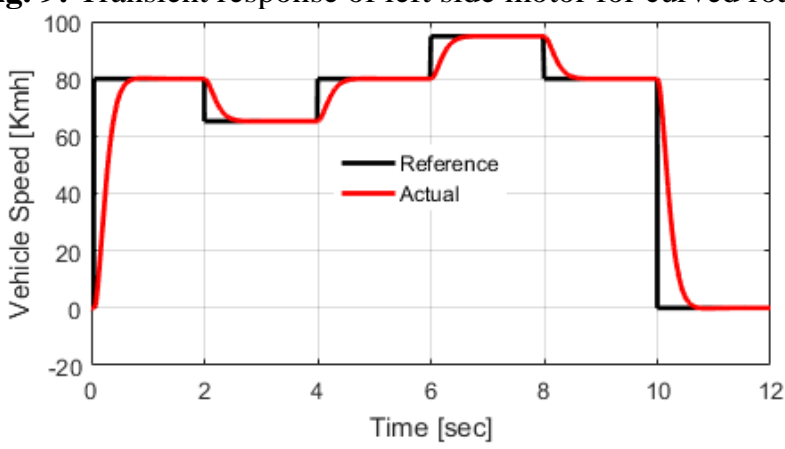

(a) Speed response with IP controller

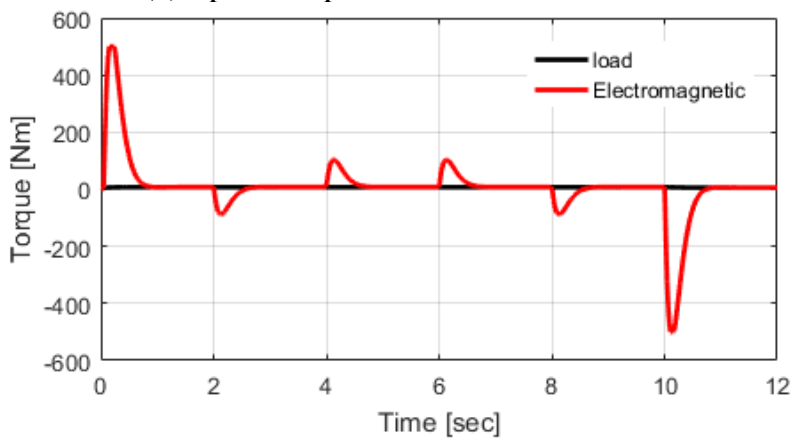

(b) Torque response with IP controller

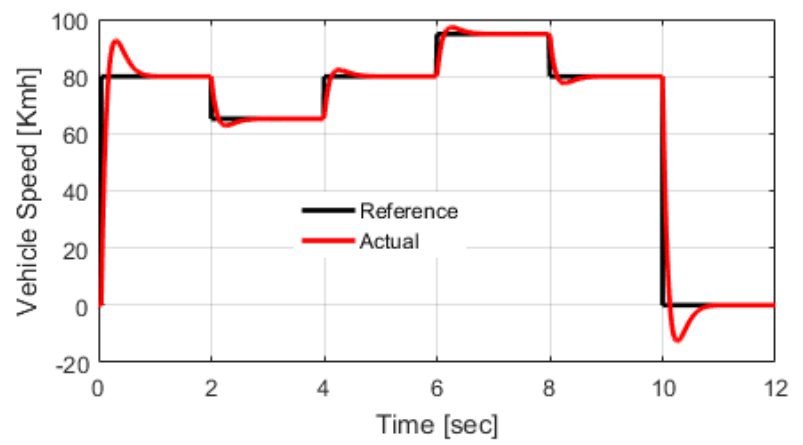

(c) Speed response with PI controller 


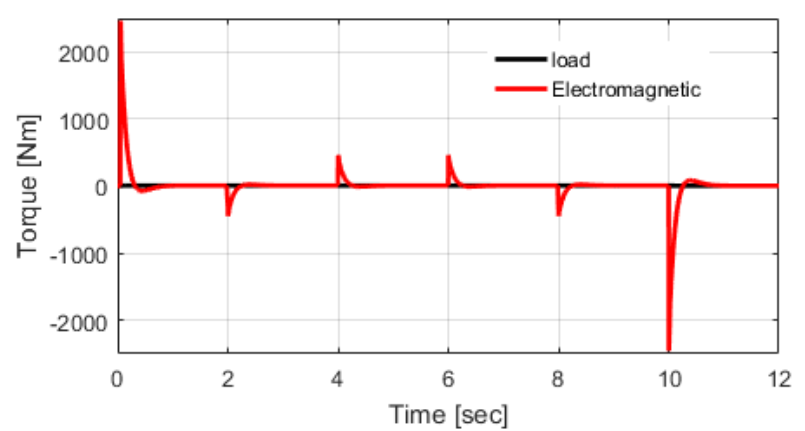

(d) Torque response with PI controller

Fig.10: Transient response of right side motor for curved road.

VIII. Conclusion

This paper has discussed about the mathematical model of DFIM and design of IP based speed control of an Electrical Vehicle. The proposed IP controller is stable under the variation of load torque and other parameter of DFIM. In the sense of overall performance of IP controllers used to be compared with that of traditional PI controlled system. From the simulation the comparative outcomes of each IP and PI controllers, it can be concluded that the two controller's performances under steady-state condition are almost same. The most positive advantage to reduce the overshoot can be obtained by the use of the proposed IP controller. In the case of two controllers against system parameters variant are also verified. It is evident from the simulation outcomes that the performance of each IP and PI is almost similar when the parameters are varied. Constructionally, there is little difference between PI and IP controllers and each implementation will be easy and simpler for that reason the use of IP controller can be more preferable than PI controller for practical application. The proposed Controller has a high efficiency, high power handling capability and easy to implement.

The simulation results show that the desired speed of a DFIM is effectively achieved by using IP controller. This control method has improved EV steering, stability and safety issue during different trajectory. The controller ensures robustness and capability to maintain ideal trajectories for two wheels control independently; it also ensures commendable disturbance control with no overshoot and steady state error. Finally, it can be concluded that the proposed IP based controller has good performance for speed control of DFIM.

\section{REFERENCES}

[1] Michael S, Vicatos, John A, Tegopoulos, "A Doubly-Fed Induction Machine Differential Drive Model for Automobiles," IEEE Trans. on Energy Conversion, Vol. 18, No. 2, pp. 225-230, 2003.

[2] Hirofumi Akagi, Hikaru Sato, "Control and Performance of a Flywhee Energy Storage System Based on a Doubly-Fed Induction GeneratorMotor," IEEE Power Electronics Specialists Conference, Vol. 27, pp. 32-39, 1999.

[3] Leonhard W., Control Electrical Drives, Germany, Springier verlag Berlin Heidelberg; 1997.

[4] Wang S, Ding Y. Stability Analysis of Field Oriented Doubly Fed Induction Machine Drive Based on Computed Simulation. Taylor \& Francis Electrical Machines and Power Systems.1993.

[5] Morel L, H.Godfroid, A.Mirzaian, J.M. Kauffmann. Double-fed induction machine: converter optimisation and field oriented control without position sensor. IEE Proc. Electr. Power Appl. 1998; 145(4):360-368p.

[6] Djurovic M. et al, "Double Fed Induction Generator with Two Pair of Poles," IEMDC Conferences of Electrical Machines and Drives, Vol 412, pp. 11-13, 1995.

[7] Longya Xu, Wei Cheng, "Torque, Reactive Power control of a Doubly Fed Induction Machine by Position Position Sensorless Scheme," IEEE Transactions on Industry Applications, Vol. 31, No. 3, pp. 636-642, 1995.
[8] Sergei Peresada, Andrea Tilli, Alberto Tonielli, "Indirect Stator FluxOriented Output Feedback Control of a Doubly Fed Induction Machine." IEEE Trans. On control Systems Technology, Vol. 11, pp. $875-888,2003$

[9] Li Zang, Hasan K H, "Neural Network Aided Energy Efficiency Control for a Field Orientation Induction Machine Drive," Proceeding of Ninth International Conference on Electrical Machine and Drives, IEE 1999; Conference Publication, No., 468

[10] David E. Rice, "A Suggested Energy-Savings Evaluation Method for AC Adjustable-Speed Drive Applications," IEEE Trans. on Industry Applications, Vol. 24, No.6 pp.1107-1117, 1988.

[11] Peter Vas. Vector Control of AC Machines. Clarendon Press; New York: Oxford University Press 1990.

[12] Wang S, Ding Y. Stability Analysis of Field Oriented Doubly Fed Induction Machine Drive Based on Computed Simulation. Taylor \& Francis Electrical Machines and Power Systems. 1993.

[13] Drid S., Nait-Said M.S., and Tadjine M., "Double flux oriented contro for the doubly fed induction motor." Electric Power Components \& Systems Journal, Vol. 33, No. 10, 2005.

[14] R. R. Riadh, M. A. Imran, A. M. Shobial, M. Shahjalal, M. A. Mannan, "Speed Control of an Inverter Fed Three-Phase Induction Motor Using IP Controller Considering Core Loss and Stray Load Loss," STM Journals Trends in Electrical Engineering, Vol. 5, pp. 28-35, 2015.

[15] M. A. Mannan, "Integral Plus Proportional Controller Based Speed Control of Direct Torque Controlled IPMSM," American Academic \& Scholarly Research Journal, Vol. 5, pp. 80-90, 2013.

\section{BIOGRAPHIES}



Al Mayhedee Zubair was born in Gopalganj, Bangladesh on December 15, 1989. He received her B.Sc. Eng. Degree in EEE from Stamford University Bangladesh, Bangladesh in 2014. At present, he is doing his Masters in Electrical and Electronic Engineering in EEE Department of American International UniversityBangladesh (AIUB), Bangladesh. His research interests are in the field of Power Electronics, control of electric motor, Renewable Energy, electric motor drive, Power System, Control System etc.

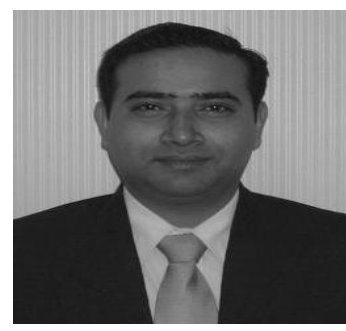

Mohammad Abdul Mannan was born in Laxmipur, Bangladesh on January 01, 1975. He received his B. Sc. Eng. Degree from Rajshahi University of Engineering and Technology (RUET former BITR), Bangladesh, in 1998, and Masters of Eng. and Dr. of Eng. degrees from Kitami Institute of Technology, Japan, in 2003 and 2006 respectively, all in electrical engineering. He then joined in the American International University Bangladesh (AIUB) as an Assistant professor on May 2006. From July 2012 he is a senior Assistant Professor in AIUB. His research interests include electric motor drive, power electronics, power system, wind generation system and control of electric motor, power electronic converters, power system, and wind generation system.

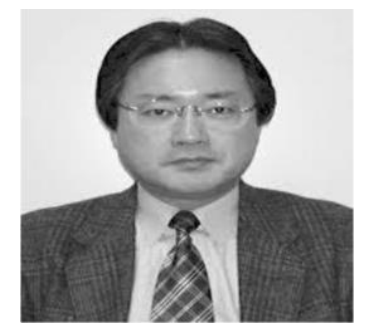

Junji Tamura was born in Hokkaido, Japan on January 17, 1957. He received his B. Sc. Eng. Degree from Muroran Institute of Technology, Japan, in 1979 and M.Sc. Eng. and Dr. Eng. degrees from Hokkaido University, Japan, in 1981 and 1984 respectively, all in electrical engineering. In 1984, he became a lecturer in 1986, and an associate professor at the Kitami Institute of Technology (KIT), Japan. He is a professor at the Kitami Institute of Technology (KIT). He is also now a vice-president for education in KIT. He is a member of the IEE of Japan and a senior member of the IEEE Power Engineering Society. 